\title{
PERTUMBUHAN DAN PEMBUNGAAN Tagetes erecta L. DENGAN PEMBERIAN BEBERAPA KOSENTRASI PACLOBUTRAZOL
}

\section{THE GROWTH AND FLOWERING Tagetes erecta L. BY GIVING SEVERAL PACLOBUTRAZOL CONCENTRATIONS}

\author{
Dwi Zulfita ${ }^{1)}$ dan Agus Hariyanti ${ }^{1)}$ \\ ${ }^{1)}$ Fakultas Pertanian Universitas Tanjungpura \\ Email: dwi.zulfita@faperta.untan.ac.id
}

\begin{abstract}
ABSTRAK
Budidaya tanaman Tagetes erecta L di Kalimantan Barat sampai saat ini belum banyak dilakukan. Usaha pengembangan budidaya tanaman $T$. erecta $\mathrm{L}$ di Kalbar mempunyai potensi dan prospek yang baik. Salah satu permasalahan budidaya tanaman $T$. erecta $\mathrm{L}$. adalah tanaman yang cukup tinggi dengan percabangan yang banyak dan mudah rebah apabila akan dijadikan tanaman hias dalam pot. Salah satu usaha yang dapat dilakukan untuk membuat tanaman ini menjadi tanaman hias pot yang memiliki nilai estetika tinggi adalah dengan pemberian zat penghambat tumbuh (growth retardant) paclobutrazol. Tujuan penelitian ini adalah mendapatkan konsentrasi paclobutrazol terbaik untuk pertumbuhan dan pembungaan $T$. erecta L. Penelitian dilakukan dengan Rancangan Acak Lengkap (RAL) dengan 4 perlakuan dan 6 ulangan yaitu $\mathrm{p}_{1}$ (Paclobutrazol konsentrasi $50 \mathrm{ppm}), \mathrm{p}_{2}=($ Paclobutrazol konsentrasi $100 \mathrm{ppm}), \mathrm{p}_{3}$ (Paclobutrazol konsentrasi $150 \mathrm{ppm}$ ) dan $\mathrm{p}_{4}$ (Paclobutrazol konsentrasi $200 \mathrm{ppm}$ ). Variabel yang diamati adalah volume akar, tinggi tanaman, waktu berbunga, jumlah kuntum bunga dan diameter bunga. Data hasil pengamatan dianalisis secara statistik dengan menggunakan analisis varians (uji $\mathrm{F}$ taraf 5\%). Apabila uji $\mathrm{F}$ menunjukkan adanya pengaruh yang nyata, maka dilanjutkan dengan uji jarak berganda Duncan pada taraf $5 \%$. Hasil penelitian menunjukkan bahwa konsentrasi paclobutrazol 200 ppm paling baik dalam mempengaruhi pertumbuhan dan pembungaan $T$. erecta $\mathrm{L}$.
\end{abstract}

Kata Kunci: paclobutrazol; pembungaan; pertumbuhan; Tagetes erecta L.

\begin{abstract}
The cultivation of Tagetes erecta L. plant in West Kalimantan has not been done much conducted. Effort to develop the plant in West Kalimantan has a good potential and prospect. One of the problems of it's cultivation is the height of the plant that is really tall with a lot of branches. When potted, this plant is likely to fall down. Making this plant more estetical can be done by giving growth retardant paclobutrazol. The purpose of this study was to obtain the best concentration of paclobutrazol for the growth and flowering of $T$. erecta $L$. The study was conducted with a completely randomized design with 4 treatments and 6 replications. Paclobutrazol concentration factors consist of 4 levels, namely p1 (Paclobutrazol concentration of $50 \mathrm{ppm}), \mathrm{p} 2=\mathrm{POC}($ Paclobutrazol concentration of $100 \mathrm{ppm}), \mathrm{p} 3$ (Paclobutrazol concentration of $150 \mathrm{ppm}$ ) and $\mathrm{p} 4$ (Paclobutrazol concentration of $200 \mathrm{ppm})$. The variables observed were including root volume, plant height, flowering time, number of flower buds and flower diameter. The observed data were statistically analyzed using analysis of variance ( $\mathrm{F}$ test level of 5\%). If the $\mathrm{F}$ test showed a significant effect, the test will be continued with Duncan's multiple range
\end{abstract}


test at 5\% level. The results showed that the concentration of paclobutrazol $200 \mathrm{ppm}$ was the best in influencing the growth and flowering of T. erecta $\mathrm{L}$.

Keywords: flowering; growth; paclobutrazol; Tagetes erecta L.

\section{PENDAHULUAN}

Tagetes erecta L. yang sering disebut dengan bunga tahi ayam atau tahi kotok berasal dari Meksiko. Tanaman ini merupakan tanaman yang memiliki batang tegak, banyak percabangan dan tingginya 1-1,5 meter. Tagetes biasanya dibudidayakan sebagai tanaman bunga potong dan tanaman pagar (Astuti, 2003 cit. Pancawati, 2014).

Tagetes erecta $\mathrm{L}$. saat ini telah banyak dibudidayakan di Indonesia, khususnya di Pulau Bali. Spesies marigold sangat beragam, di antaranya adalah $T$. erecta, $T$. patula, $T$. minuta, T. lucida,T. tenuifolia dan T. filifolia. Tagetes dapat tumbuh sepanjang tahun, mudah ditanam dan umur panen relatif singkat, sehingga banyak dibudidayakan untuk dijadikan tanaman hias, bunga dekorasi dan bunga sesaji. Namun jarang digunakan sebagai bunga hias pot karena ukuran tanaman yang cukup tinggi dengan percabangan yang banyak dan tanaman yang mudah rebah. Oleh karena itu perlu perlakuan khusus untuk membuat tanaman ini menjadi tanaman hias pot yang memiliki nilai estetika yang tinggi dengan membuat tanaman menjadi pendek. Salah satu caranya adalah dengan pemberian zat penghambat tumbuh (growth retardant) yaitu paclobutrazol (Wilkinson dan Richard, 1987).

Paclobutrazol merupakan salah satu zat penghambat pertumbuhan tanaman dan termasuk zat pengatur tumbuh eksogen. Zat penghambat tumbuh adalah senyawa pengatur tumbuh yang dapat menghambat proses fisiologis dan biokimia dalam tubuh tumbuhan (Weaver, 1992). Cathey 1975 cit. Retno (2009) mendefinisikan zat penghambat tumbuh adalah senyawa organik yang menghambat perpanjangan batang, meningkatkan warna hijau dari daun dan secara tidak langsung mempengaruhi pembungaan tanpa menyebabkan pertumbuhan abnormal. Growth retardant berkemampuan untuk menghambat biosintesis giberelin. Oleh karena itu senyawa 
retardant lebih banyak dikenal dengan nama anti giberelin (Wattimena, 1988).

Paclobutrazol merupakan turunan pirimidin yang memiliki rumus empirik $\quad \mathrm{C}_{15} \mathrm{H}_{20} \mathrm{ClN}_{3} \mathrm{O}$ (Santriasrini, 2009). Mekanisme kerja paclobutrazol adalah menghambat produksi giberelin dengan cara menghambat oksidasi kaurene menjadi asam kaurenat, yang selanjutnya dapat menyebabkan pengurangan kecepatan dalam pembelahan sel, pengurangan pertumbuhan vegetatif, dan secara tidak langsung akan mengalihkan asimilat ke pertumbuhan reproduktif untuk pembentukan bunga dan perkembangan buah (Weaver, 1992; ICI, 1984).

\section{Beberapa}

penelitian menunjukkan hasil yang baik untuk pengggunaan paclobutrazol terhadap tanaman hias. Pemberian paclobutrazol pada krisan mengurangi pertumbuhan akar dan menyebabkan perubahan morfologi. Paclobutrazol dapat diberikan melalui akar atau daun. Paclobutrazol bersifat menghambat biosintesa giberellin (GA) (Ermawati, 2013; Darussalam, 2014).
Penelitian ini bertujuan mendapatkan konsentrasi paclobutrazol yang terbaik untuk pertumbuhan dan pembungaan Tagetes erecta $\mathrm{L}$.

\section{METODE}

\section{Tempat dan Waktu Penelitian}

Penelitian ini dilakukan di Kecamatan Pontianak Tenggara, Kota Pontianak dengan ketinggian tempat 0-1 meter di atas permukaan air laut. Penelitian dilaksanakan 10 Oktober sampai 12 Desember 2019.

\section{Bahan dan Alat}

Bahan yang digunakan adalah benih $T$. erecta L. varietas Maharani F1 Orange, paclobutrazol, aquades, tanah gambut $8 \mathrm{~kg} /$ polybag, pupuk kotoran ayam, pupuk Urea 3.5 g/polybag, pupuk SP-36, pupuk 2.5 g/polybag $\mathrm{KCl} 1.5$ g/polybag, kapur dolomit $\left(\mathrm{CaCO}_{3}\right) 10.27$ g/polybag, polybag berukuran $40 \times 60 \mathrm{~cm}$ berwarna hitam, insektisida (Furadan), Alika $1 \mathrm{ml} / \mathrm{l}$ air, dan abu bakaran 100 g/polybag.

Alat yang digunakan adalah thermohigrometer, cangkul, ayakan, umbrometer, wadah penyemaian (babybag), ember, gelas ukur, 
micropipet, gembor, plang dan label, penggaris, meteran, alat tulis, alat dokumentasi, handsprayer, dan jangka sorong.

\section{Metode Penelitian}

Penelitian

dilakukan menggunakan Rancangan Acak Lengkap (RAL), terdiri dari 4 taraf perlakuan konsentrasi paclobutrazol dan 6 ulangan. Perlakuan yang dimaksud adalah $\mathrm{p}_{1}$ (Paclobutrazol konsentrasi 50 ppm), $\mathrm{p}_{2}$ (Paclobutrazol $\begin{array}{llll}\text { konsentrasi } & 100 & \mathrm{ppm}), \quad \mathrm{p}_{3}\end{array}$ (Paclobutrazol konsentrasi 150 ppm) dan $\mathrm{p}_{4}$ (Paclobutrazol konsentrasi 200 ppm).

\section{Prosedur Penelitian}

Penelitian dilakukan menggunakan polybag (40x60) $\mathrm{cm}$ dengan berat tanah $10 \mathrm{~kg}$. Sebelum penyemaian, terlebih dahulu dilakukan seleksi benih Tagetes dengan cara memisahkan benih yang rusak atau cacat, keriput dan berjamur dengan penilaian secara kasat mata. Kemudian benih direndam dengan aquades selama \pm 15 menit untuk mempercepat perkecambahan. Penyemaian benih dilakukan dalam polybag kecil dan diberi naungan paranet. Bibit dipindahkan dari media persemaian ke polybag setelah berumur 18 hari dengan kriteria bibit telah memiliki 6 helai daun yang membuka sempurna dan tinggi $14 \mathrm{~cm}$. Media tanam yang digunakan adalah tanah gambut sebanyak $8 \mathrm{~kg} /$ polybag dan dicampur pupuk kotoran ayam (500 g) dan kapur dolomit (10.27 g) secara merata, kemudian tanah diinkubasi selama 3 minggu.

\section{Penanaman}

Bibit yang ditanam pada setiap polybag adalah 1 bibit per lubang tanam pada kedalaman $8 \mathrm{~cm}$ Setelah penanaman selesai, ditaburi insektisida (Furadan sebanyak satu sendok teh) mengelilingi bibit pada polybag. Pemeliharaan tanaman meliputi penyulaman dilakukan satu minggu setelah tanam terhadap tanaman yang mati. Penyiraman dilakukan 2 kali sehari dengan takaran $600 \mathrm{ml} /$ polybag (kapasitas lapangan). Pemasangan ajir pada saat tanaman berumur 14 hari setelah pindah tanam.

Aplikasi paclobutrazol sesuai konsentrasi perlakuan dengan cara menyemprotkan larutan paclobutrazol pada daun dan batang tanaman sampai membasahi seluruh tanaman. Aplikasi 
dimulai pada saat tanaman berumur 6 hari setelah tanam sampai panen dengan frekuensi 3 hari sekali.

Pencegahan terhadap hama dan penyakit dilakukan secara kimiawi dengan memberikan furadan pada semaian dan saat pindah tanam untuk mengendalikan siput. Alika untuk mencegah hama ulat dan belalang, serta pellet Aespro diberikan pada sekeliling tanaman di luar polybag saat terjadi serangan hama molusca.

Variabel yang diamati adalah volume akar $\left(\mathrm{cm}^{3}\right)$, tinggi tanaman (cm), waktu berbunga (HST), jumlah kuntum bunga per tanaman (kuntum) dan diameter bunga $(\mathrm{cm})$.

\section{Analisis Data}

Data hasil pengamatan dianalisis menggunakan analisis varians (uji $\mathrm{F}$ taraf 5\%). Apabila uji F menunjukkan pengaruh nyata, maka uji dilanjutkan dengan uji jarak berganda Duncan pada taraf $5 \%$.

\section{HASIL DAN PEMBAHASAN}

Hasil sidik ragam menunjukkan bahwa pemberian berbagai konsentrasi paclobutrazol berpengaruh nyata terhadap tinggi tanaman, umur berbunga dan diameter bunga, tetapi berpengaruh tidak nyata terhadap jumlah kuntum bunga per tanaman. Hasil uji DNMRT disajikan pada Tabel 1 dan keragaan tanaman $T$. erecta $\mathrm{L}$ pada berbagai konsentrasi paclobutrazol dapat dilihat pada Gambar 1.

Tabel 1. Rerata Volume Akar, Tinggi Tanaman, Waktu Berbunga, Jumlah Kuntum Bunga dan Diameter Bunga dengan Beberapa Konsentrasi Paclobutrazol

\begin{tabular}{cccccc}
\hline \multirow{2}{*}{$\begin{array}{c}\text { Konsentrasi } \\
\text { Paclobutrazol } \\
(\mathrm{ppm})\end{array}$} & $\begin{array}{c}\text { Volume } \\
\text { Akar }(\mathrm{cm})\end{array}$ & $\begin{array}{c}\text { Tinggi } \\
\text { Tanaman } \\
(\mathrm{cm})\end{array}$ & $\begin{array}{c}\text { Waktu } \\
\text { Berbunga } \\
(\mathrm{hst})\end{array}$ & $\begin{array}{c}\text { Jumlah } \\
\text { Kuntum Bunga } \\
(\text { kuntum })\end{array}$ & $\begin{array}{c}\text { Diameter } \\
\text { Bunga (cm) }\end{array}$ \\
\hline 50 & $6,54 \mathrm{~b}$ & $56,44 \mathrm{a}$ & $22,00 \mathrm{a}$ & $10,32 \mathrm{~b}$ & $7,54 \mathrm{~b}$ \\
100 & $9,15 \mathrm{~b}$ & $48,62 \mathrm{~b}$ & $20,74 \mathrm{ab}$ & $12,85 \mathrm{~b}$ & $8,34 \mathrm{~b}$ \\
150 & $8,38 \mathrm{~b}$ & $46,76 \mathrm{~b}$ & $20,04 \mathrm{~b}$ & $10,74 \mathrm{~b}$ & $8,41 \mathrm{~b}$ \\
200 & $13,15 \mathrm{a}$ & $46,70 \mathrm{~b}$ & $19,50 \mathrm{~b}$ & $18,60 \mathrm{a}$ & $9,05 \mathrm{a}$ \\
\hline KK $(\%)$ & 3,72 & 10,10 & 14,09 & 9,46 & 17,94 \\
\hline
\end{tabular}

Keterangan: Angka-angka pada kolom yang sama yang diikuti oleh huruf yang sama tidak berbeda nyata menurut uji DMRT pada taraf $\alpha=5 \%$ 


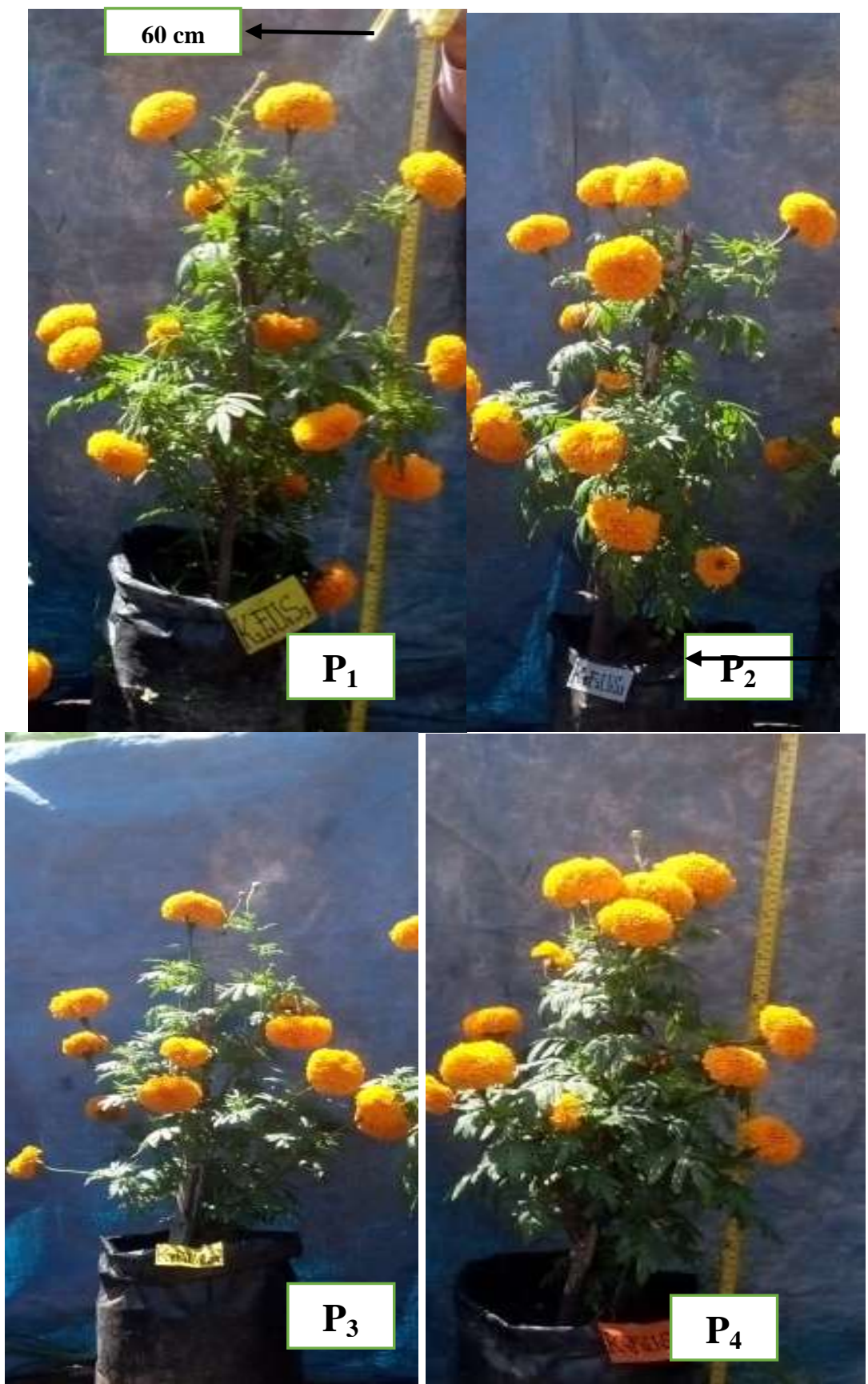

Gambar 1. Keragaan Tanaman Tagetes erecta L pada Akhir Penelitian $\mathrm{p}_{1}$ (paclobutrazol konsentrasi $50 \mathrm{ppm}$ ), $\mathrm{p}_{2}$ (paclobutrazol konsentrasi 100 $\mathrm{ppm}), \mathrm{p}_{3}$ (paclobutrazol konsentrasi $\left.150 \mathrm{ppm}\right), \mathrm{p}_{4}$ (paclobutrazol konsentrasi $200 \mathrm{ppm}$ )

Tabel 1 menunjukkan bahwa pemberian berbagai konsentrasi Paclobutrazol berbeda nyata terhadap volume akar, tinggi tanaman, waktu berbunga, jumlah kuntum bunga per tanaman dan diameter bunga. Nilai tertinggi terdapat pada perlakuan pemberian paclobutrazol konsentrasi 200 ppm dan berbeda nyata dengan pemberian Paclobutrazol konsentrasi 50, 
100 dan 150 ppm pada variabel volume akar, jumlah kuntum bunga per tanaman dan diameter bunga tetapi pada variabel tinggi tanaman dan waktu berbunga, pemberian paclobutrazol konsentrasi 200 ppm memberikan nilai terendah dan berbeda nyata dengan pemberian konsentrasi 50 ppm. Ini artinya pemberian paclobutrazol konsentrasi 200 ppm menunjukkan tinggi tanaman yang paling rendah dan waktu berbunga yang paling cepat walaupun tidak berbeda dengan pemberian paclobutrazol konsentrasi 100 ppm dan $150 \mathrm{ppm}$.

Menurut Wahyurini (2010), secara fisiologis paclobutrazol berperan dalam menekan perpanjangan batang karena aktivitas paclobutrazol dapat menghambat biosintesis giberelin sehingga menyebabkan penurunan laju pembelahan sel dan menghambat pertumbuhan vegetatif dan mendorong pertumbuhan reproduktif seperti pembentukan bunga. Pemanjangan batang tanaman akan terhambat, diameter batang bertambah dan secara tidak langsung pembungaan terjadi lebih cepat bersamaan (serempak) tanpa menyebabkan tanaman menjadi abnormal (Cathey, 1975 cit. Retno, 2009).
Tinggi tanaman terendah ditunjukkan pada pemberian paclobutrazol konsentrasi 200 ppm yaitu $46,70 \mathrm{~cm}$. Hal ini menunjukkan semakin tinggi jumlah larutan paclobutrazol yang diberikan ke tanaman Tagetes maka tanaman akan semakin rendah. Hasil ini sesuai dengan pendapat Putri (2015), bahwa semakin tinggi konsentrasi paclobutrazol yang diberikan akan menghambat tinggi tanaman bunga matahari dan semakin efektif bila diberikan saat tanaman masih muda. Tinggi tanaman yang terendah pada penelitian ini lebih rendah dari pada tinggi tanaman Tagetes varietas Maharani F1 Orange menurut deskripsinya yaitu $50-150 \mathrm{~cm}$.

Tinggi tanaman merupakan pemanjangan dan pembelahan sel-sel meristem apikal yang distimulasi oleh zat pengatur tumbuh giberelin. Kinerja paclobutrazol adalah menghambat pembentukan dan kerja giberelin, serta merangsang kerusakan giberelin oleh karena itu terjadi kekurangan giberelin yang menyebabkan tanaman kerdil. Sejalan dengan pengerdilan batang ada beberapa bagian tanaman yang ikut mengerdil adalah panjang tangkai bunga, dan ukuran daun (luas daun). Tsegaw dkk., 2005 yang menujukkan paclobutrazol memperpendek tinggi 
batang kentang dengan menurunkan $43.5 \%$ kandungan giberelin.

Pemberian berbagai konsentrasi paclobutrazol mempengaruhi volume akar tanaman dengan meningkatkan rambut akar dan diameter akar (Tsegaw dkk., 2005) sehingga membantu meningkatkan penyerapan unsur hara melalui pembuluh xylem bersama-sama dengan molekul-molekul air dan dapat meningkatkan klorofil daun terutama unsur $\mathrm{N}$ dan $\mathrm{Mg}$. Hal itu mendukung terjadinya proses metabolisme yang baik pada jaringan tanaman khususnya untuk fotosintesis. Paclobutrazol juga mampu meningkatkan karbohidrat jaringan kayu, distribusi asimilat dari daun ke akar, meningkatkan respirasi akar, dan mengurangi kehilangan air di akar (Sya'bani, 2011).

Berdasarkan penelitian diperoleh hasil bahwa paclobutrazol menghambat pembentukan giberelin yang membuat tanaman menjadi kerdil, hal ini sesuai dengan penelitian Sinniah, et al. (2012) yaitu menghambat pembentukan giberelin. Paclobutrazol menghambat pembentukan giberelin dengan cara menghambat proses oksidase enzim kaurene untuk membentuk asam kaurenat sehingga terjadi penghambatan sintesis giberelin pada fase awal pembentukan giberelin (Akhsari dan
Sukamoto, 2008). Jadi serapan hara yang diangkut melalui pembuluh xylem ke daun dan digunakan untuk proses fotosintesis menghasilkan fotosintat yang selanjutnya akan ditranslokasikan ke organ reproduktif sehingga merangsang pembungaan yang dalam hal ini berhubungan dengan waktu berbunga Tagetes juga lebih cepat dibandingkan deskripsi tanaman dan membentuk bunga secara visual juga lebih baik.

Waktu berbunga pada pemberian paclobutrazol konsentrasi 200 ppm tidak berbeda nyata dengan pemberian paclobutrazol konsentrasi 100 ppm dan 150 ppm. Jumlah kuntum bunga yang paling banyak dan diameter bunga paling besar dihasilkan pada pemberian paclobutrazol konsentrasi 200 ppm yaitu berturut-turut 18,60 kuntum dan 9,05 $\mathrm{cm}$. Jumlah kuntum bunga pertanaman yang dihasilkan pada penelitian ini lebih banyak dibandingkan dengan deskripsi tanaman $T$. erecta L. varietas Maharani F1 Orange (kisaran 7-10 cm).

Penelitian ini membuktikan bahwa paclobutrazol dapat meningkatkan pembungaan pada konsentrasi yang tepat (Salisbury dan Ross., 1992). Lama penyinaran penting untuk pertumbuhan tanaman terutama pada proses fotosintesis. Semakin tinggi intensitas 
cahaya yang diterima tanaman akan mempercepat waktu pembungaan (Sambeka, et al., 2012). Penelitian ini membenarkan bahwa paclobutrazol menghambat pertumbuhan vegetatif dan mempercepat perkembangan reproduktif. Hasil ini sesuai dengan penelitian Rahim, et al. (2011) bahwa pemberian paclobutrazol pada mangga dapat memicu terbentuknya bunga.

\section{KESIMPULAN DAN SARAN}

\section{Kesimpulan}

Pemberian berbagai konsentrasi Paclobutrazol mempengaruhi pertumbuhan dan pembungaan $T$. erecta L. Tinggi tanaman tidak berbeda antara pemberian paclobutrazol konsentrasi 100 sampai dengan 200 ppm. Perlakuan paclobutrazol dengan konsentrasi 200 ppm mengakibatkan jumlah bunga paling banyak dan diameter bunga paling besar.

\section{Saran}

Dari hasil penelitian disarankan penggunaan Paclobutrazol dengan konsentrasi 200 ttinggi sehingga dapat memberikan pertumbuhan yang baik tanaman yang tinggi sehingga tingkat kerebahan tanaman bisa diatai..

\section{DAFTAR PUSTAKA}

Darussalam. 2014. Pengaruh Paklobutrazol dan Sitokinin terhadap Pertumbuhan Batang Serta Biji Padi Hitam (Oryza sativa L. 'Cempo Ireng'). Thesis Universitas Gadjah Mada. Yogyakarta.

Ermawati, D. 2013. Pengaruh Konsentrasi Paclobutrazol terhadap Pertumbuhan Tanaman Bunga Krisan (Chrysanthemum sp). Skripsi. Jurusan Budi Daya Pertanian, Fakultas Pertanian. Institut Pertanian Bogor. Bogor.

Pancawati, S. 2014. Pengaruh Perlakuan Paclobutrazol terhadap Tanaman Tagetes (Tagetes erecta L.) sebagai Upaya Mengubah Fungsi menjadi Tanaman Pot Hias. Skripsi. Fakultas Biologi. Universitas Jendral Soedirman. Purwokerto.

Putri. L.A.P., 2015. Pengaruh Waktu dan Konsentrasi Paclobutrazol terhadap Pertumbuhan Bunga Matahari (Hellianthus annuus L.). Skripsi USU. Medan.

Rahim, A.O.S.A., O.M. Elamin dan F.K. Bangert., 2011. Effects of Growth Retardant, Paclobutrazol (PB2) and Prohexaclone-Ca on Flozal Induction Regular Bearing Mango (Mangifera indica L) Cultivars During offseason. ARPN Journal of Agricultural and Biological Science. 6 (3) :18-26.

Salisbury, F.B., and C.W. Ross. 1992. Fisiologi Tumbuhan Jilid 2. Terjemahan dari: FB Salisbury 
and CW Ross. Plant Physiology. 57(4) :13-18.

Sambeka, F., D.R. Samuel dan R.X. Johanes. 2012. Efektifitas Waktu Pemberian dan Konsentrasi Paclobutrazol terhadap Pertumbuhan dan Hasil Kentang (Solanum tuberosum L.) Varietas Supejohn. Skripsi. Fakultas Pertanian Universitas Sam Ratulangi. Manado.

Santriasrini, R. 2009. Pengaruh Paclobutrazol terhadap Pertumbuhan dan Pembungaan Gloksinia (Sinningia speciosa Pink). Skripsi. Jurusan Budi Daya Pertanian. Institut Pertanian Bogor. Bogor.

Sya'bani, N.J. 2011. Pengaruh Paclobutrazol terhadap Karakteristik Fisiologis dan Hasil Kacang Tanah (Arachis hypogea L.) Varietas Sima dan Kelinci. Skripsi. Departemen Agronomi dan Hortikultura. Institut Pertanian Bogor. Bogor.

Tsegaw, T., S. Hammes. And J. Robbertse. 2005. PaclobutrazolIncluced Leaf, Stem, and Root Anatomical Modification in Potato. Hor tScience. 40(5): 1343-1346.

Wahyurini, E. 2010. Stimulasi Pertumbuhan dan Pertambahan beberapa Kultivar Lili (Lilinium longiflozum) dengan Aplikasi $\mathrm{GA}_{3}$ dan Paclobutrazol. Jurnal Agrivet. 14:27-35.

Wattimena, G. A. 1988. Zat Pengatur Tumbuh Tanaman. Pusat Antar Universitas (PAU) Bioteknologi IPB. Bogor. 145(309): 12-104.
Weaver, R. J. 1992. Plant Growth Substances in Agriculture. W. H. Freeman and Co. San Francisco. 121: 151162.

Wilkinson, R.I. and D. Richards. 1987. Effect of Paclobutrazol on Growth and Flowering of Bouvardia Humbolddtii. Hort Science 22: $444-445$. 